\title{
A PROPRIEDADE INTELECTUAL NA ERA DA INFORMAÇÃO: UMA ABORDAGEM HISTÓRICA ACERCA DOS DIREITOS DO AUTOR E A SUA (IN)ADEQUAÇÃO À ATUAL SOCIEDADE EM REDE
}

\section{THE INTELLECTUAL PROPERTY IN THE INFORMATION AGE: AN HISTORICAL APPROACH ABOUT THE AUTHOR'S RIGHTS AND IT'S (UN)SUITABILITY TO THE CURRENT NETWORK SOCIETY}

\author{
MARINA DE BEM CASANOVA \\ Acadêmica do curso de direito na Universidade Federal de Santa Maria/RS. \\ MAURÍCIO ARPINI QUINTANA \\ Acadêmico do curso de direito na Universidade Federal de Santa Maria/RS.
}

\begin{abstract}
RESUMO
Em meio ao século XV, Johannes Gutenberg inventava a prensa móvel e, com ela, a possibilidade de que fossem realizadas incontáveis réplicas das obras. Surgia, assim, a necessidade de uma maior proteção dos direitos do autor, não por mera questão de vanglória, mas, também, pela justeza na extração de valor econômico do trabalho. Posteriormente, em 1969, com a invenção da primeira rede de computadores, a possibilidade de replicação de obras foi catapultada para um nível até então inimaginável. Não obstante tudo isso, a legislação autoral, essencialmente internacional, não apresentou grandes mudanças ao longo dos anos. Dessa forma, este artigo pretende demonstrar, por meio de pesquisa bibliográfica de cunho exploratório, a parcial obsolescência do tratamento legal despendido aos direitos autorais, uma vez que o rigor excessivo na proteção do autor termina gerando dificuldades não só ao acesso à cultura, mas também à própria criação e desenvolvimento de novas ideias.
\end{abstract}

Palavras-chave: cultura; direitos do autor; sociedade em rede.

\begin{abstract}
Amid the fifteenth century, Johannes Gutenberg was inventing the printing press and, with it, the possibility that countless copies of the works could be made. It appeared, therefore, the need of greater protection of the rights of the author, not a mere matter of boasting, but also for fairness in extracting economic value of the work. Later, in 1969, with the invention of the first computer network, the possibility of replication works was catapulted to a level previously unimaginable. Notwithstanding all this, the copyright law, which is essentially international, showed no significant changes over the years. Thus, we intend to demonstrate, through a bibliographic research with an exploratory character, the obsolescence of legal treatment expended to copyright legislation, since the hardship in protecting the author ends up creating difficulties not only to the access to culture, but also to own creation and development of new ideas.
\end{abstract}

Keywords: culture; author's rights; network society.

\section{SUMÁRIO}

INTRODUÇAO; 1 OS DIREITOS AUTORAIS E SUA EVOLUÇÃO; 2 OS DIREITOS DO AUTOR NA LEGISLAÇÃO BRASILEIRA; 3 A CRIAÇÃO E O DESENVOLVIMENTO DA INTERNET; 4 O DIREITO DO AUTOR NA SOCIEDADE DA INFORMAÇÃO; CONCLUSÃO; REFERÊNCIAS. 


\section{INTRODUÇÃO}

Durante o período renascentista, com o desenvolvimento do comércio e, conseguintemente, das relações de consumo, iniciou-se uma acentuada produção artística, sobretudo em função do mecenato, cujo funcionamento, por meio do patrocínio fornecido pelos mecenas, incentivava a produção artística e literária da época ${ }^{1}$. No entanto, ainda assim, são poucas as obras do período cinquecento que possuam a assinatura de seu autor. Foi, com efeito, somente com o surgimento da possibilidade de replicação das obras em larga escala, iniciada com a invenção da prensa por Johannes Gutenberg e sua posterior viabilidade econômica, que a preocupação de se atribuir um autor a determinando trabalho assume papel de relevo (não só no aspecto físico, mas também sobre a obra propriamente dita, considerada imaterialmente ${ }^{2}$ ).

Surgia, assim, a importância de uma proteção legal aos direitos autorais, porquanto a necessidade de que o artista tivesse determinada obra identificada como sua deixava de ser simples questão de vaidade e passava a ser fundamental para posterior comercialização da obra que então se tornava possível. Diante dessa situação, tem-se, como marco inicial do tratamento legislativo da matéria, a promulgação, na Inglaterra, do Estatuto da Rainha Ana, datado de 1710, de caráter essencialmente privatista ${ }^{3}$. Carecia-se, contudo, mormente em virtude da cada vez maior integração econômica entre os países, de uma legislação internacional acerca do tema, pelo que tomaram forma, durante o final do XIX, as Convenções de Paris e Berna ${ }^{4}$.

Malgrado toda a matéria legal desenvolvida, até mesmo após o surgimento do acordo TRIPS (Acordo Sobre Aspectos dos Direitos de Propriedade Intelectual Relacionados ao Comércio) em 1994, não houve grandes alterações nas normas que tratam da matéria, as quais, entende-se, não mais se coadunam com o atual desenvolvimento social em que nos deparamos, no qual a transmissão de conteúdo por meio da internet ocorre de maneira quase instantânea. A limitação exagerada imposta pela legislação impede o necessário acesso, que a própria internet muito bem provê, à propriedade intelectual já existente, prejudicando, pois, a capacidade de ampliar, gerar e propagar conhecimento e cultura.

\footnotetext{
${ }^{1}$ NETTO, José Carlos Costa. Direito Autoral no Brasil. São Paulo: FTD, 1998, p. 33.

${ }^{2}$ CAUQUELIN, Anne. Arte Contemporânea - Uma Introdução. São Paulo: Martins Fontes, 2005, p. 28.

${ }^{3}$ ASCENSÃO, José de Oliveira. Direito Autoral. Rio de Janeiro: Renovar, 1997, p. 4.

4 BASSO, Maristela. O Direito Internacional da Propriedade Intelectual. Porto Alegre: Livraria do Advogado, 2000. p. 25.
} 

SUA (IN)ADEQUAÇÃO À ATUAL SOCIEDADE EM REDE.

Pretende-se, portanto, por meio de pesquisa bibliográfica de cunho exploratório ${ }^{5}$, demonstrar a relativa inadequação do modelo de proteção hoje existente. A ideia é que não se desestimule a criação, mantendo-se a recompensa econômica pela inovação, sem, todavia, impedir o progresso cultural, social e tecnológico.

Para tanto, o artigo será estruturado em quatro partes. Iniciar-se-á por uma breve história da evolução dos direitos autorais, passando-se ao estudo da atual legislação brasileira sobre o tema; após, será explicado o surgimento da internet, finalizando-se com as inadequações do sistema vigente e as atuais alternativas para seu ajustamento.

\section{OS DIREITOS AUTORIAS E SUA EVOLUÇÃO}

A primeira legislação a versar sobre os direitos do autor foi promulgada na Inglaterra, no século XVIII; popularmente conhecida como o Estatuto da Rainha Ana ${ }^{6}$, seu nome completo era "An Act for the Encouragement of Learning, by Vesting the Copies of Printed Books in the Authors or Purchasers of such Copies, during the Times therein mentioned" ("um ato para o encorajamento da erudição por meio da concessão das cópias de livros impressos aos seus autores ou aos compradores de tais cópias durante os termos dentro mencionados", em livre tradução) e tinha por objetivo primordial a transformação de uma relação privada (entre o artista e o mecena) em uma relação pública, visando a estimular a formação de conhecimento. Surgia, aí, a expressão copyright (direito de cópia), posteriormente empregada em outros países, e que, até hoje, é internacionalmente utilizada em referência aos direitos autorais ${ }^{7}$.

Logo após, em tempos de Revolução Francesa, surgiu, na França, uma nova corrente do direito autoral, com vistas à proteção do autor propriamente dito. Era o droit d'auteur, que teve por objetivo, lançando mão dos institutos jurídicos da época, dar ao autor direito de propriedade sobre seu trabalho, incluindo a propriedade intelectual no rol de direitos reais ${ }^{8}$. Com o passar dos anos, percebeu-se que a mera propriedade era insuficiente para atender às

${ }^{5}$ Conforme Antônio Gil, essas pesquisas "têm como objetivo proporcionar maior familiaridade com o problema, com vistas a torná-lo mais explícito ou a constituir hipóteses”. In: GIL, Antônio Carlos. Como Elaborar Projetos de Pesquisa. São Paulo: Atlas, 2002. p. 41.

${ }^{6}$ ASCENSÃO, José de Oliveira. Opus Citatum. p. 4.

${ }^{7}$ BASSO, Maristela. Opus Citatum. p. 70-71.

8 CONSElHO NACIONAL DE PESQUISA E PÓS-GRADUAÇÃO EM DIREITO, XVIII., 2009, São Paulo. Anais eletrônicos. São Paulo. Disponível em: <http://www.publicadireito.com.br/conpedi/manaus/arquivos/Anais/sao_paulo/2535.pdf>. Acesso em: 6 jul. 2013. 
A PROPRIEDADE INTELECTUAL NA ERA DA INFORMAÇÃO: UMA ABORDAGEM HISTÓRICA ACERCA DOS DIREITOS DO AUTOR E A SUA (IN)ADEQUAÇÃO À ATUAL SOCIEDADE EM REDE.

necessidades dos criadores, adotando-se, conseguintemente, um sistema dúplice, assegurando ao autor direitos de propriedade e personalidade.

A partir de então, inicia-se um irreversível e necessário processo de internacionalização dos direitos relativos à propriedade intelectual. É o que ensina Maristela Basso:

Independente do modelo conceitual adotado - tradicional ou atual - os direitos decorrentes da produção intelectual têm caráter imaterial e são essencialmente internacionais, cosmopolitas [...].

[Também sábias as palavras de] Edmond Picard, que, mesmo antes da Convenção de Berna de 1886, ensinava que 'a produção do espírito, objeto do direito intelectual, destina-se naturalmente a expandir-se para todos os lugares onde vai a civilização. Ela é divisível ao infinito, mas permanece sempre uma. 0 autor de um livro, o inventor de um processo industrial, aquele que produziu uma obra musical ou uma obra suscetível de ser divulgada por não importa qual arte ou desenho, certamente não trabalhou unicamente para seu pequeno mundo, no qual ele vive, nem mesmo para a nação à qual ele pertence. Seu desejo, sua esperança, é de ver seu trabalho se expandir. Sua intensidade não se perde, mas, ao se expandir, adquire um vigor novo. 0 que, para uma coisa material, implicaria em impossibilidade ou destruição, se torna, para uma coisa intelectual, uma oportunidade de força e de celebridade'.

Esta passagem de Picard pode ser completada pelas palavras do professorJoseph Kohler, proferidas durante a Conferência de Berlim, também relativas aos direitos do autor: 'Como nós trabalhamos para a unificação de um direito que, mais que qualquer outro, se destina a ser internacional, permito-me fazer algumas digressões históricas do direito de autor para tocar, em seguida, no aspecto internacional da questão. Não é somente do fim do século XVIII que data o direito de autor. A ideia surgiu já no século XV, depois da descoberta, de dimensões incalculáveis, da arte de imprimir, que é um título de glória para a Alemanha. [...] Mas, foi o século XIX que deu vida às muitas leis sobre a matéria, se bem que as nações rivalizavam por melhor proteger o direito intelectual... Contudo, no século passado, a proteção apresentava ainda grandes lacunas, e a maior delas era o exagero na ideia de nacionalidade. Este exagero deveria ser vencido pela ideia de que as nações civilizadas formam uma grande Sociedade chamada a executar, por seus esforços comuns, as grandes tarefas da cultura humana. A primeira condições desta comunidade de povos é a máxima de que o direito do espírito é reconhecido, não somente pela nação a qual pertence o homem criador, mas por todos os Estados. Qualquer um que tenha criado uma obra do pensamento deve ter seu direito em todos os lugares do mundo, porque ele não é somente membro da nação - ele é membro da humanidade... [...]'. A especificidade desses direitos, seu caráter imaterial e sua irresistível vocação internacional ficam evidentes nas passagens citadas. ${ }^{9}$

Diante dessa premência de mundialização, nasceu, em 1883, a Convenção de Paris para a Proteção da Propriedade Industrial, cujo objetivo era a regulamentação sobre patentes, modelos de utilidade, desenhos e modelos industriais, marcas etc., prevendo uma autonomia legislativa aos Estados-Membros, mas (e era esse seu principal objetivo), uma vez garantido um direito ao cidadão de um País, o mesmo tratamento deveria ser despendido aos nacionais de

${ }^{9}$ BASSO, Maristela. Opus Citatum. p. 19-21. 
outros países ${ }^{10}$. Em suma, "o tratamento dado ao nacional beneficiará também o estrangeiro" ${ }^{11}$. De igual forma, em 1886, surgiu a Convenção de Berna para Proteção das Obras Literárias e Artísticas, atualmente administrada pela Organização Mundial de Proteção Intelectual (OMPI, criada em 1967), servindo como instrumento-padrão a disciplinar os direitos do autor, vigente, ainda, na maioria dos países integrantes da Organização Mundial do Comércio ${ }^{12}$.

Após isso, posto que tenham sido firmados alguns tratados, o regime da propriedade intelectual permaneceu sem maiores alterações no âmbito internacional. Somente em 1994, com a insatisfação de algumas nações, que consideravam insuficiente a proteção dada à propriedade intelectual, foi assinado, no final da Rodada Uruguai no Acordo Geral de Tarifas e Troca, o Acordo Sobre Aspectos dos Direitos de Propriedade Intelectual Relacionados ao Comércio (TRIPS), cujos objetivos principais eram sanar as deficiências do sistema da OMPI e vincular os direitos da propriedade intelectual ao comércio mundial. Conforme assevera Maristela Basso:

O TRIPS representa, portanto, um documento fundamental na consolidação da proteção dos direitos de propriedade intelectual na sociedade internacional contemporânea, e a vinculação definitiva desses direitos ao comércio internacional. Com ele as partes ganharam e perderam alguma coisa, e os interesses contrapostos acabaram chegando ao consenso. ${ }^{13}$

É essa, basicamente, a evolução dos direitos autorais. Percebe-se, com efeito, que o conteúdo se manteve, em grande parte, inalterado, tendo havido tão somente a preocupação de harmonizá-lo mundialmente, a fim de que não houvesse discrepâncias entre os ordenamentos.

\section{OS DIREITOS DO AUTOR NA LEGISLAÇÃO BRASILEIRA}

No Brasil, a Lei no 9.610/1998 é a responsável pelo tratamento dos direitos autorais. Inspirando-se nas legislações já consolidadas em outros países, como a própria Convenção de Berna, o legislador ainda tomou o cuidado de respeitar os incisos XXVII e XXVIII do art. $5^{\circ}$ da Constituição Federal ${ }^{14}$.

\footnotetext{
10 Idem, ibidem. p. 73-74.

11 BARBOSA, Denis Borges. Uma Introdução à Propriedade Intelectual. Rio de Janeiro: Lumen Juris, 2003. p.183.

12 BASSO, Maristela. Opus Citatum. p. 90-91.

13 Idem, ibidem. p. 169.

${ }^{14}$ Art. $5^{\circ}$ Todos são iguais perante a lei, sem distinção de qualquer natureza, garantindo-se aos brasileiros e aos estrangeiros residentes no País a inviolabilidade do direito à vida, à liberdade, à igualdade, à segurança e à propriedade, nos termos seguintes:
} 

SUA (IN)ADEQUAÇÃO À ATUAL SOCIEDADE EM REDE.

Também tratou de manter expressa a diferenciação existente entre os direitos morais (entendidos como o direito do autor de ver seu nome reconhecido e citado - previstos no art. 24 da atual legislação sobre o tema) e os direitos patrimoniais do autor (a retribuição econômica a ser recebida em virtude da criação - previstos nos arts. 28 a 45). Sobre essa importante dicotomia, oportuna é a lição trazida por Carlos Alberto Bittar:

[...] os direitos autorais não se cingem, nem à categoria dos direitos reais, de que se revestem apenas os direitos denominados patrimoniais, nem à dos direitos pessoais, em que se alojam os direitos morais. Exatamente porque se bipartem nos dois citados feixes de direitos - mas que, em análise de fundo, estão, por sua natureza e sua finalidade, intimamente ligados, em conjunto incindível - não podem os direitos autorais se enquadrar nesta ou naquela das categorias citadas, mas constituem nova modalidade de direitos privados. ${ }^{15}$

Ainda, optando por modificar a legislação anterior, que previa prazo vitalício para a proteção dos direitos do autor após seu óbito, a nova Lei, em seu art. 41, fixou em setenta anos o prazo para proteção dos direitos patrimoniais, contados do dia $1^{\circ}$ de janeiro do ano subsequente ao falecimento, bem como estipulou igual prazo (para direitos patrimoniais de obras anônimas ou pseudônimas) para proteção em vida, contados do primeiro dia do ano posterior à primeira publicação. A ideia, muito claramente, foi incentivar a criação e a produção artística e literária, na medida em que, após o prazo, a obra cai em domínio público.

0 art. 46 da Lei Autoral prevê as hipóteses de exceção, isto é, quando é lícita a reprodução, utilização e representação de trabalhos independentemente da autorização de seu criador. Esse rol, que elenca oito incisos acerca do tema, é evidentemente taxativo, descabendo a sua extensão a outras situações que não as nele previstas. A intenção do legislador aparenta

$[\ldots]$

XXVII - aos autores pertence o direito exclusivo de utilização, publicação ou reprodução de suas obras, transmissível aos herdeiros pelo tempo que a lei fixar;

XXVIII - são assegurados, nos termos da lei:

a) a proteção às participações individuais em obras coletivas e à reprodução da imagem e voz humanas, inclusive nas atividades desportivas;

b) o direito de fiscalização do aproveitamento econômico das obras que criarem ou de que participarem aos criadores, aos intérpretes e às respectivas representações sindicais e associativas.

BRASIL. Constituição Federal. Brasília: Senado Federal, $1988 . \quad$ Disponível em: <http://www.planalto.gov.br/ccivil_03/constituicao/constituicao.htm>. Acesso em: 29 abr. 2013.

${ }^{15}$ BITTAR, Carlos Alberto. Direito do autor. Rio de Janeiro: Forense Universitária, 2001. p. 11. 
A PROPRIEDADE INTELECTUAL NA ERA DA INFORMAÇÃO: UMA ABORDAGEM HISTÓRICA ACERCA DOS DIREITOS DO AUTOR E A SUA (IN)ADEQUAÇÃO À ATUAL SOCIEDADE EM REDE.

MARINA DE BEM CASANOVA, MAURÍCIO ARPINI QUINTANA

ter sido a de propiciar a utilização não econômica da obra ${ }^{16}$, valorizando o caráter social e educativo.

No campo da música, manteve-se o tratamento despendido anteriormente, vinculando à autorização prévia do autor qualquer adaptação, sob pena de suspensão imediata da execução musical. O Escritório Central de Arrecadação e Distribuição (ECAD) segue responsável pela arrecadação dos montantes relativos à execução pública das obras, sejam elas nacionais ou estrangeiras; em seu estatuto, o ECAD bem delimita sua área de atuação:

O ECAD praticará em nome próprio todos os atos necessários à administração e defesa dos direitos de sua competência, agindo como substituto processual, na forma prevista no $\S 2^{\circ}$ do art. 99 da Lei n. ${ }^{\circ} 9.610 / 98$, podendo autorizar ou proibir a execução pública de obras musicais, lítero-musicais e de fonogramas, inclusive por meio da radiodifusão e transmissão por qualquer modalidade, e da exibição de obras audiovisuais, podendo, ainda, fixar preços e efetuar a respectiva arrecadação e distribuição em todo o território nacional. ${ }^{17}$

Hodiernamente, a dinamicidade no compartilhamento das informações, proporcionada pela internet, vem gerando tensão entre os usuários e o Escritório, muito em função de que a cobrança de valores tidos como abusivos não seriam compatíveis com a nova era da informação. Apenas a título ilustrativo, uma das reclamações por parte dos blogueiros e demais utentes da web é a cobrança havida apenas pela divulgação de um link, direcionando o usuário ao sítio detentor do conteúdo (como o Youtube, por exemplo); segundo entendem, na medida em que o site que efetivamente expõe o conteúdo já procedeu ao pagamento da taxa, não haveria necessidade de nova cobrança por mera divulgação, sob pena de configuração de bis in idem.

${ }^{16}$ Convém ressaltar, contudo, os casos contidos nos incisos III e VIII do art. 46, que prevêem a possibilidade de exploração econômica de uma obra, ainda que esta contenha pequenos trechos de outras preexistentes, in verbis:

Art. 46. Não constitui ofensa aos direitos autorais:

[...]

III - a citação em livros, jornais, revistas ou qualquer outro meio de comunicação, de passagens de qualquer obra, para fins de estudo, crítica ou polêmica, na medida justificada para o fim a atingir, indicando-se o nome do autor e a origem da obra;

[...]

VIII - a reprodução, em quaisquer obras, de pequenos trechos de obras preexistentes, de qualquer natureza, ou de obra integral, quando de artes plásticas, sempre que a reprodução em si não seja o objetivo principal da obra nova e que não prejudique a exploração normal da obra reproduzida nem cause um prejuízo injustificado aos legítimos interesses dos autores.

BRASIL. Lei $\mathrm{n}^{\circ} 9.610$ de 19 de fevereiro de 1998. Altera, atualiza e consolida a legislação sobre direitos autorais e dá outras providências. In: Diário Oficial da República Federativa do Brasil, Brasília, DF, 20 fev. 1998. Disponível em: <http://www.planalto.gov.br/ccivil_03/leis/l9610.htm> Acesso em: 18 abr. 2013.

17 ESCRITÓRIO CENTRAL DE ARRECADAÇÃO E DISTRIBUIÇÃO. Site Oficial. Disponível em: <http://www.ecad.org.br/viewcontroller/publico/conteudo.aspx?codigo=138>. Acesso em: 18 abr. 2013. 

SUA (IN)ADEQUAÇÃO À ATUAL SOCIEDADE EM REDE.

As discussões se acirram, sobretudo em razão de que a Legislação que trata da matéria data de 1998, quando a internet ainda estava em estágio inicial em nosso País. Necessária, então, a análise de certos aspectos dessa Lei sob a ótica desta nova era da informação em que nos encontramos.

\section{A CRIAÇÃO E O DESENVOLVIMENTO DA INTERNET}

O projeto de criação da internet teve por sustentáculo as pesquisas da Agência de Projetos de Pesquisa Avançada (ARPA) do Departamento de Defesa dos Estados Unidos da América. Com efeito, em tempos de Guerra Fria, o lançamento do Sputnik por parte do governo soviético, no final da década de cinquenta, assustou sobremaneira a cúpula norte-americana, fazendo com que a ARPA desenvolvesse projetos visando à criação de um sistema de comunicação que fosse inviolável pela nação inimiga ${ }^{18}$.

Após algumas pesquisas, surgia, em $1^{\circ}$ de setembro de 1969, a ARPANET, primeira rede de computadores, que consistia na troca de mensagens independentemente de um sistema de controle central $^{19}$. De caráter essencialmente militar, a sua utilização em centros de pesquisa tornou difícil a separação entre comunicações oficiais e meras conversas de cunho pessoal.

Em 28 de fevereiro de 1990, tem-se o fechamento da ARPANET e, quase que concomitantemente, o surgimento da World Wide Web (WWW), cujo funcionamento através de interface gráfica permitia uma melhor utilização do serviço. Sobre a implementação da teia mundial, melhor explica Manuel Castells:

[...] por volta de 1990 os não-iniciados ainda tinham dificuldade para usar a Internet. A capacidade de transmissão de gráficos era muito limitada, e era dificílimo localizar e receber informações. Um novo salto tecnológico permitiu a difusão da Internet na sociedade em geral: a criação de um novo aplicativo, a teia mundial (world wide web - WWW), que organizada o teor dos sítios da Internet por informação, oferecendo aos usuários um sistema fácil de pesquisa para procurar as informações desejadas. ${ }^{20}$

\footnotetext{
${ }^{18}$ CASTELLS, Manuel. A sociedade em rede - a era da informação: economia, sociedade e cultura. São Paulo: Paz e Terra, 2005, p. 82.

19 ROHRMANN, Carlos Alberto. O governo da internet: Uma análise sob a ótica do direito das telecomunicações. Disponível em: <http://www.egov.ufsc.br/portal/sites/default/files/anexos/2953829554-1-PB.pdf>. Acesso em: 10 jul. 2013.

${ }^{20}$ CASTELLS, Manuel. Opus citatum. p. 87-88.
} 
Inventado na Europa, pelo Centre Européen poour Recherche Nucleaire (CERN), o software não foi montado segundo a tradição da extinta ARPANET, mas sim com a contribuição com a cultura hacker da década de 70. Influenciados pelas ideias de Ted Nelson, socialista norte-americano, e com vistas a possibilitar ao povo a utilização dos computadores em seu próprio proveito, o CERN criou, ainda, uma linguagem de marcação de hipertexto (hypertex markup language - HTML), um protocolo de transferência de hipertexto (hypertext transfer protocol - HTTP) e um localizador uniforme de recursos (uniform resource locator - URL) ${ }^{21}$.

Satisfeito com o resultado, o Centro liberou o WWW gratuitamente na internet. A partir daí, diversos centros de pesquisa passaram a criar os primeiros sítios da web e, posteriormente, deu-se surgimento dos navegadores, difundindo-se a internet pelo mundo, "criando uma verdadeira teia mundial" 22 .

\section{O DIREITO DO AUTOR NA SOCIEDADE DA INFORMAÇÃO}

A internet revolucionou, pois, a circulação de informações pelo mundo e, por consequência, alterou drasticamente o processo criativo. O Direito, então, tem a (necessária) tarefa de se adaptar a essas mudanças, sob pena de engessamento da sociedade. Sábias, nesse sentido, as palavras de Niklas Luhmann, renomado sociólogo conhecido pelo trabalho visando a aprofundar o estudo da relação entre a estrutura social e o Direito:

A sociedade garante aos outros sistemas um ambiente por assim dizer domesticado, de menor complexidade, um ambiente no qual já está excluída a aleatoriedade das possibilidades, fazendo assim com que ele apresente menos exigências à estrutura do sistema. Nesse sentido a estrutura da sociedade possuiu uma função de desafogo para os sistemas parciais formados na sociedade. Essa correlação é válida também no sentido inverso: na medida em que os sistemas na sociedade sejam capazes de suportar um ambiente mais complexo - seja por sua organização ou por amor - a sociedade como um todo pode ganhar em complexidade e tornar possíveis formas mais variadas de experimentar e do agir. ${ }^{23}$

Um desses "sistemas parciais" referidos por Luhmann é o próprio Direito. Para o autor, então, não só a estrutura social é alterada pelo Direito, como também o inverso acontece, isto

\footnotetext{
${ }^{21}$ Idem, ibidem.

22 Idem, ibidem, p.89.

${ }^{23}$ LUHMANN, Niklas. Sociologia do Direito, vol. 1. Rio de Janeiro: Edições Tempo Brasileiro, 1983, p. 168.
} 
A PROPRIEDADE INTELECTUAL NA ERA DA INFORMAÇÃO: UMA ABORDAGEM HISTÓRICA ACERCA DOS DIREITOS DO AUTOR E A SUA (IN)ADEQUAÇÃO À ATUAL SOCIEDADE EM REDE.

é, as complexidades e a contingência social criam a necessidade de modificação nas estruturas da sociedade (dentre elas, assim, o Direito). Segue ele:

Essa inversão do raciocínio altera também as condições para a avaliação da relação entre a sociedade e o direito. Com isso supera-ser a base do pensamento em termos de direito natural, ao estilo europeu tradicional. [...] A legalidade resulta muito mais dos problemas de complexidade e contingência que precisam ser resolvidos, se é que deva ter lugar alguma interação e até mesmo constituição de sentido.

Sendo assim, o direito tem que ser visto como uma estrutura cujos limites e cujas formas de seleção são definidos pelo sistema social. Ele não é de nenhuma forma a única estrutura social: além do direito devem ser consideradas as estruturas cognitivas, os meios de comunicação (como por exemplo a verdade ou o amor), e principalmente a institucionalização do esquema de diferenciação do sistemas na sociedade. Mas o direito é imprescindível enquanto estrutura, porque sem a generalização congruente de expectativas comportamentais normativas os homens não podem orientar-se entre si, não podem esperar suas expectativas. E essa estrutura tem que ser institucionalizada ao nível da própria sociedade, pois só aqui podem ser criadas aquelas instâncias que domesticam o ambiente para outros sistemas sociais. Ela se modifica, portanto, com a evolução da complexidade social.

$[\ldots]$

Hoje, a teoria da evolução não pode mais ser interpretada como um processo causal simples, como uma relação de causa e efeito, para então se referir a categorias morais de interpretação de sentido da evolução como 'progresso'. Ela tem que recorrer às concepções da teoria de sistemas, que podem esclarecer por que as mudanças estruturais, improváveis a partir do ângulo da situação antiga, podem ser estabilizadas como conquistas evolutivas [...] por que em outras palavras novas combinações se tornam sustentáveis a partir de riscos e vantagens maiores. ${ }^{24}$

Conclui-se, assim, com Luhmann, que, para cada expectativa normativa, há necessidade de aferição dos seus riscos e vantagens. Isso porque o sistema não pode permanecer estático em virtude do engessamento de um de seus componentes (aqui, o Direito), mas também não pode ser desestabilizado pela normatização de todas as novas situações do sistema social ${ }^{25}$.

\footnotetext{
${ }^{24}$ Idem, ibidem.

${ }^{25}$ Ainda sobre o assunto, assevera Miguel Reale:

[...] nada de estranhável que, nas fases iniciais da civilização, o milagre da forma e a sedução dos modelos se tenham imposto ao homem como algo de válido em si mesmo, verificando-se o paradoxo de uma subordinação aos ritos jurídicos tanto mais acentuada quanto menos percebido o seu significado real. Foi só com o processar-se da civilização que a humanidade tornou objeto de ciência as formas plasmadoras da ação, adquirindo, paulatinamente, consciência do que representa, como instrumento de liberdade, a conversão dos rituais jurídicos em forma operacionais e em técnicas de formalização. Talvez se possa dizer que a história do Direito assinala uma libertação das formas abstratas opressivas, graças à compreensão do sentido concreto da forma (Gestalt).

[...] a tipificação normativa não é, por conseguinte, uma obra cerebrina ou imaginosa, fruto de um querer arbitrário, mas sim o resultado de uma análise positiva de dados empíricos, análise essa que culmina sempre num ato decisório, na eleição de uma dentre duas ou mais soluções possíveis.
} 

SUA (IN)ADEQUAÇÃO À ATUAL SOCIEDADE EM REDE.

Dessa forma, no tocante aos direitos autorais, forçoso verificar se a atual disciplina legal não estaria obstando o próprio objetivo inicial da matéria, isto é, fomentar o processo criativo e, consequentemente, o desenvolvimento tecnológico e cultural. Para tanto, necessária a apreciação de alguns artigos da Lei 9.610/98.

O principal problema da legislação atual é sua restritividade, dificultando, assim, o acesso à informação e à cultura. Tanto é assim que a Organização Não Governamental Consumers International qualificou o Brasil, em 2011, como o país com a quarta pior lei autoral do mundo ${ }^{26}$. Convém notar, nesse sentido, o disposto no inciso IX do artigo 29 da Lei dos Direitos Autorais:

Art. 29. Depende de autorização prévia e expressa do autor a utilização da obra, por quaisquer modalidades, tais como: $[\ldots]$

IX - a inclusão em base de dados, o armazenamento em computador, a microfilmagem e as demais formas de arquivamento do gênero; ${ }^{27}$

Percebe-se, portanto, que, pela grafia do dispositivo, resta proibido até mesmo armazenar, em computador, o conteúdo de um CD legalmente adquirido, ainda que somente visando a convertê-lo em formato diverso, para fins de ouvi-lo em um iPod, por exemplo. A hipótese, evidentemente, coloca inúmeras pessoas em situação de ilegalidade, na medida em que tal proceder é comumente realizado no Brasil.

Além dessa desconformidade, a referida Lei ainda limita de maneira inexplicável a dita cópia privada. Veja-se o que traz o seu artigo 46, inciso II:

Art. 46. Não constitui ofensa aos direitos autorais:

[...]

II - a reprodução, em um só exemplar de pequenos trechos, para uso privado do copista, desde que feita por este, sem intuito de lucro;

A questão veio alterar o disposto na antiga Lei 5.988/73 e no art. 666, IV, do Código Civil de 1916, que permitiam a cópia manuscrita desde que não houvesse finalidade de lucro com a reprodução obtida. Não obstante a nova legislação ter mantido uma limitação ${ }^{2829}$ (isto é, uma

REALE, Miguel apud BASSO, Maristela. Opus Citatum.

${ }^{26}$ CONSURMERS INTERNATIONAL. Consumers International's website. Disponível em: <http://www.consumersinternational.org/news-and-media/news/2011/04/brazil, -egypt-and-uk-amongworst-copyright-regimes-in-the-world\#.UXA6qKKG021>. Acesso em: 18 abr. 2013.

${ }^{27}$ BRASIL. Lei $n^{\circ} 9.610$ de 19 de fevereiro de 1998. Opus citatum.

${ }^{28}$ Também o fez, convém consignar, em seu art. $8^{\circ}$, in verbis:

Art. $8^{\circ}$ Não são objeto de proteção como direitos autorais de que trata esta Lei:

I - as idéias, procedimentos normativos, sistemas, métodos, projetos ou conceitos matemáticos como tais;

II - os esquemas, planos ou regras para realizar atos mentais, jogos ou negócios; 

SUA (IN)ADEQUAÇÃO À ATUAL SOCIEDADE EM REDE.

hipótese de não incidência) aos direitos do autor, fez-lo de maneira por demais restrita. Primeiramente, é de nota o conceito extremamente subjetivo da expressão "pequenos trechos". Não há nada na Lei regulamentando a questão, adotando-se, por parte de algumas pessoas, sobretudo em universidades, o consenso de que pequenos trechos seriam capítulos de uma obra, posto que isso não encontre qualquer sustentáculo legal. Por segundo, a Lei novamente inclui milhares de pessoas em situação ilícita; a utilização de cópias, para fins acadêmicos ou de entretenimento, é conduta, hoje, tão difundida e de tão fácil execução no País, especialmente porque o conteúdo é disponibilizado na rede, que a fiscalização se torna deveras complicada - se o policiamento dessa conduta já era difícil em tempos passados, o que dizer, hoje, em que a cópia pode ser efetuada em casa, com apenas alguns cliques. Sobre a necessidade de utilização de obras alheias sem qualquer tipo de intermediação, sabiamente refere Sérgio Branco Junior:

Se é claro que não é possível permitir o livre e irrestrito uso das obras alheias na elaboração de novas obras, também não é possível vetar de modo absoluto todo e qualquer uso da obra de terceiros, já que esse extremo impediria, de maneira muito mais acentuada e perniciosa, o desenvolvimento social. ${ }^{30}$

Com efeito, é fato notório que a inventividade humana jamais ocorre ex nihilo, ou seja, uma obra necessariamente será inspirada em outra que a precedeu. Nesse sentido, aliás, a célebre frase escrita por Isaac Newton: "se enxerguei mais longe é porque me apoiei nos ombros de gigantes" - metáfora, a propósito, que Newton extraiu da obra de Bernard de Chartres (nanos gigantum humeris insidentes - somos anões apoiados sobre os ombros de gigantes) ${ }^{31}$.

III - os formulários em branco para serem preenchidos por qualquer tipo de informação, científica ou não, e suas instruções;

IV - os textos de tratados ou convenções, leis, decretos, regulamentos, decisões judiciais e demais atos oficiais;

V - as informações de uso comum tais como calendários, agendas, cadastros ou legendas;

$\mathrm{VI}$ - os nomes e títulos isolados;

VII - o aproveitamento industrial ou comercial das idéias contidas nas obras.

Idem, ibidem.

${ }^{29} \mathrm{E}$ limitações, diga-se, são deveras relevantes como forma de garantia de acesso à informação, de modo que, posto que importante o estímulo à criação por meio da proteção conferida por intermédio dos direitos autorias, também é necessário restringí-los em determinadas situações. Nesse sentido, a sempre oportuna lição de Bruno Jorge Hammes: "juntamente com a aceitação do Direito de Autor, desenvolveu-se o reconhecimento de que o mesmo está sujeito igualmente a uma vinculação social. Em nome do interesse comum, o autor deve tolerar restrições aos seus direitos". HAMMES, Bruno Jorge. 0 direito de propriedade intelectual: subsídios para o ensino. São Leopoldo: Editora Unisinos, 1998, p. 76-77.

${ }_{30}$ JÚNIOR, Sérgio Vieira Branco. Direitos Autorais na internet e o uso de obras alheias. Rio de Janeiro: Lumen Juris, 2007. p. 63.

${ }^{31}$ EVERYTHING IS A REMIX. Produção de Kirby Ferguson. Disponível em: <http://www.everythingisaremix.info/watch-the-series/>. Acesso em: 18 abr. 2013. 

SUA (IN)ADEQUAÇÃO À ATUAL SOCIEDADE EM REDE.

Em tempos de internet e do acesso praticamente irrestrito à propriedade intelectual já existente por ela potencializado, surgem iniciativas de copyleft ${ }^{32}$, como forma de garantir meios de produção de conhecimento, dentre as quais se destaca a Creative Commons (CC). A iniciativa CC é uma organização sem fins lucrativos que "permite o compartilhamento e o uso da criatividade e do conhecimento através de licenças jurídicas gratuitas ${ }^{33}$ ". A ideia surgiu em contraproposta à licença copyright, uma vez que esta, ao proteger uma obra, fazia com que dela automaticamente constasse o selo "todos os direitos reservados".

Portanto, com o tempo, percebeu-se que o autor não necessariamente se importava com a utilização de sua obra por terceiros, desde que pela nova criação recebesse o devido crédito nominal. A internet, por sua vez, vira a ferramenta perfeita para que o autor exponha sua pretensão à sociedade, estimulando a utilização de sua obra e a criação de novos trabalhos a partir dela.

Ao vincular um trabalho ao Creative Commons, o autor opta por uma alternativa às normas tradicionais da propriedade intelectual, podendo ele próprio estipular (e limitar) o acesso ao seu trabalho, da forma que melhor lhe convier. Afinal, conforme diz o slogan da organização, “tudo pode ser mais fácil quando você não precisa de intermediários ${ }^{34 ” . ~}$

Surgido nos Estados Unidos, o CC já se encontra em mais de quarenta países. No Brasil, organiza-se em parceria com a Escola de Direito da Fundação Getulio Vargas, responsável pela tradução das licenças, adaptando-as à legislação brasileira. Foi este o resultado:

Atribuição (by): [...] permite que outros distribuam, remixem, adaptem ou criem obras derivadas, mesmo que para uso com fins comerciais, contanto que seja dado crédito pela criação original. Esta é a licença menos restritiva de todas as oferecidas, em termos de quais usos outras pessoas podem fazer de sua obra.

Atribuição - Compartilhamento pela mesma Licença (by-sa): [...] permite que outros remixem, adaptem, e criem obras derivadas ainda que para fins comerciais, contanto que o crédito seja atribuído ao autor e que essas obras sejam licenciadas sob os mesmos termos. [...]

\footnotetext{
32 O termo copyleft advém de flagrante trocadilho com a expressão copyright, indicando a proposta de inversão trazida por essa nova corrente. Esta, muito mais flexível que a original, visa a reservar parcialmente os direitos de autoria sobre determinado trabalho, de modo que qualquer outro tenha a oportunidade de, modificando trabalho já existente, produzir obra própria, desde que licencie sua obra em copyleft, entregando ao autor do original crédito nominal pela contribuição.

33 CREATIVE COMMONS (CC). Creative Commons website. Disponível em: <http://creativecommons.org.br/o-que-e-o-cc/>. Acesso em: 21 abr. 2013.

${ }^{34}$ CREATIVE COMMONS $\quad$ (CC). Creative Commons website. Disponivel em: <http://dl.dropboxusercontent.com/u/102874773/Get-Creative-nova-versao.swf >. Acesso em: 24 abr. 2013.
} 

SUA (IN)ADEQUAÇÃO À ATUAL SOCIEDADE EM REDE.

Atribuição - Não a Obras Derivadas (by-nd): [...] permite a redistribuição e o uso para fins comerciais e não comerciais, contanto que a obra seja redistribuída sem modificações e completa, e que os créditos sejam atribuídos ao autor.

Atribuição - Uso Não Comercial (by-nc): [...] permite que outros remixem, adaptem, e criem obras derivadas sobre a obra licenciada, sendo vedado o uso com fins comerciais. As novas obras devem conter menção ao autor nos créditos e também não podem ser usadas com fins comerciais, porém as obras derivadas não precisam ser licenciadas sob os mesmos termos desta licença.

Atribuição - Uso Não Comercial - Compartilhamento pela mesma Licença (by-ncsa): [...] permite que outros remixem, adaptem e criem obras derivadas sobre a obra original, desde que com fins não comerciais e contanto que atribuam crédito ao autor e licenciem as novas criações sob os mesmos parâmetros. Outros podem fazer o download ou redistribuir a obra da mesma forma que na licença anterior, mas eles também podem traduzir, fazer remixes e elaborar novas histórias com base na obra original. Toda nova obra feita a partir desta deverá ser licenciada com a mesma licença, de modo que qualquer obra derivada, por natureza, não poderá ser usada para fins comerciais.

Atribuição - Uso Não Comercial - Não a Obras Derivadas (by-nc-nd): [...] é a mais restritiva [...], permitindo redistribuição. Ela é comumente chamada "propaganda grátis" pois permite que outros façam download das obras licenciadas e as compartilhem, contanto que mencionem o autor, mas sem poder modificar a obra de nenhuma forma, nem utilizá-la para fins comerciais. ${ }^{35}$

Essas licenças podem ser livremente utilizadas e combinadas entre si para qualquer obra detentora de direito autoral. A partir disso, com a atual mundialização do CC, qualquer pessoa, em qualquer lugar do planeta, ao encontrar uma obra licenciada, pode, de forma extremamente prosaica, entender qual forma de uso the foi autorizada pelo criador.

Esse tipo de modelo colaborativo se mostra deveras salutar, sobretudo em países como o Brasil, cujo regime jurídico autoral ainda não se coaduna perfeitamente com a atual sociedade da informação. Contribui, pois, para um maior desenvolvimento cultural, aumentando o domínio público e, conseguintemente, incentivando a produção intelectual.

$\mathrm{Na}$ tentativa de minimizar as discrepâncias entre a atual legislação e as novas tecnologias, tramita na Câmara dos Deputados o Projeto de Lei $n^{\circ} 3.133 / 2012$, de iniciativa do Deputado Nazareno Fonteles, propondo uma série de alterações na lei vigente. Segundo o autor, o objetivo é justamente adaptá-la à utilização dos meios digitais para veiculação de trabalhos intelectuais ${ }^{36}$.

Uma das elogiáveis alterações previstas no projeto é a possibilidade de reprodução (inclusive armazenamento eletrônico), distribuição e comunicação ao público de obras de cunho

\footnotetext{
${ }^{35}$ CREATIVE COMMONS (CC). Creative Commons website. Disponível em: <http://creativecommons.org.br/as-licencas/>. Acesso em: 24 abr. 2013.

${ }^{36}$ CAMMARA DOS DEPUTADOS. Site Oficial. Disponível em: <http:// www2.camara.leg.br/camaranoticias/noticias/EDUCACAO-E-CULTURA/409666-PROJETO-PROPOEREFORMA-NA-LEI-DE-DIREITO-AUTORAL.html>. Acesso em: 29 abr. 2013.
} 
intelectual, desde que a iniciativa, sem prejudicar os interesses dos autores, vise unicamente a fins educacionais, à informação e à pesquisa para fins criativos. Se aprovada a reforma, será possível, por exemplo, que bibliotecas, museus e quaisquer outros centros de armazenagem de documentos reproduzam obras (sem finalidade comercial), colocando-as à disposição do público para estudo e pesquisa, sem a necessidade de prévia autorização.

\section{CONCLUSÃO}

Percebe-se, assim, que, nos últimos anos, passou-se por período de forte desenvolvimento tecnológico, sobretudo no âmbito da internet, a qual trouxe consigo inúmeras alternativas à difusão de informação. Inegável, também, que essas alterações afeta(ra)m sobremaneira a questão dos direitos autorais, cuja legislação, no Brasil, data do longínquo ano de 1998.

Portanto, é preciso rever certas determinações, com intuito de adequá-las a esta nova era da informação. Com efeito, forçoso que se mantenha uma dicotomia querer-poder em relação à propriedade intelectual, isto é, é importante que as pessoas queiram criar (e, para tanto, devem receber reconhecimento moral e patrimonial por seu trabalho), sem, em contrapartida, obstar-lhes a utilização de obras alheias para o implemento de novas ideias. É importante notar que, em tempos atuais, a utilização de uma cópia por alguém não implica a necessária proibição de que terceiro também a utilize; isso porque, hoje, há a possibilidade de compartilhamento sem interesse comercial, contribuindo, assim, para a democratização da cultura.

Hoje, além do Projeto de Lei $n^{\circ} 3.133 / 2012$, que tramita na Câmara dos Deputados, existem algumas iniciativas com vistas a facilitar a difusão da informação e cultura. É o caso, por exemplo, da Organização Creative Commons, que possibilita ao autor abrir mão de certas garantias legais, expondo a todos, de uma maneira simples e global, a sua pretensão.

Essa forma de modelo colaborativo tem potencializado a criação e difusão de obras intelectuais até então protegidas por uma lei rígida e açambarcadora. 0 sucesso dessas alternativas revela a premente necessidade de adequação do tratamento despendido, na medida em que temos, hodiernamente, um verdadeiro estancamento do tema, ainda tratado por normas cuja elaboração data de época em que web recém engatinhava em nosso País. 


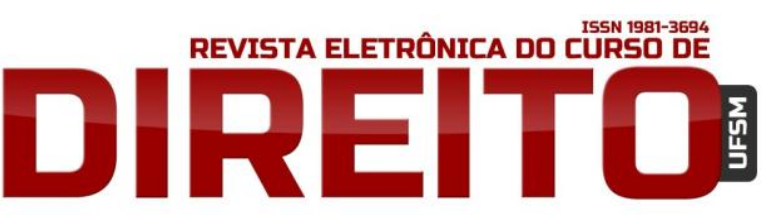

A PROPRIEDADE INTELECTUAL NA ERA DA INFORMAÇÃO: UMA ABORDAGEM HISTÓRICA ACERCA DOS DIREITOS DO AUTOR E A SUA (IN)ADEQUAÇÃO À ATUAL SOCIEDADE EM REDE.

A questão é, pois, que a tutela dos direitos intelectuais pelos mesmos meios empregados antes do surgimento da internet vai de encontro à própria essência desses direitos (o incentivo ao desenvolvimento cultural e tecnológico), porque, de acordo com o manejo atual da matéria, impede-se a geração colaborativa do conteúdo, o que é típico do ambiente on-line. Essa transformação se mostra salutar, conseguintemente, com o fito de adequar os atuais institutos jurídicos à realidade social hoje vivida (afinal, é possível afirmar, como visto, que o Direito é constantemente alterado pela estrutura social), em que a informação circula ampla e livremente, fomentando a propagação da cultura, da tecnologia e da criação colaborativa.

\section{REFERÊNCIAS}

ASCENSÃO, José de Oliveira. Direito Autoral. Rio de Janeiro: Renovar, 1997.

BARBOSA, Denis Borges. Uma Introdução à Propriedade Intelectual. Rio de Janeiro: Lumen Juris, 2003.

BASSO, Maristela. O Direito Internacional da Propriedade Intelectual. Porto Alegre: Livraria do Advogado, 2000.

BITTAR, Carlos Alberto. Direito do autor. Rio de Janeiro: Forense Universitária, 2001.

BRASIL. Constituição Federal. Brasília: Senado Federal, 1988. Disponível em: <http://www.planalto.gov.br/ccivil_03/constituicao/constituicao.htm >. Acesso em: 29 abr. 2013.

BRASIL. Lei $n^{\circ} 9.610$ de 19 de fevereiro de 1998. Altera, atualiza e consolida a legislação sobre direitos autorais e dá outras providências. In: Diário Oficial da República Federativa do Brasil, Brasília, DF, 20 fev. 1998. Disponível em:

<http://www.planalto.gov.br/ccivil_03/leis/19610.htm> Acesso em: 18 abr. 2013.

CÂMARA DOS DEPUTADOS. Site da Câmara. Disponível em:

<http://www2.camara.leg.br/camaranoticias/noticias/EDUCACAO-E-CULTURA/409666-

PROJETO-PROPOE-REFORMA-NA-LEI-DE-DIREITO-AUTORAL.html>. Acesso em: 29 abr. 2013.

CASTELLS, Manuel. A sociedade em rede - a era da informação: economia, sociedade e cultura.

São Paulo: Paz e Terra, 2005.

CAUQUELIN, Anne. Arte Contemporânea - Uma Introdução. São Paulo: Martins Fontes, 2005.

CONSELHO NACIONAL DE PESQUISA E PÓS-GRADUAÇÃO EM DIREITO, XVIII., 2009, São Paulo. Anais eletrônicos.

São Paulo.

Disponível

em: 


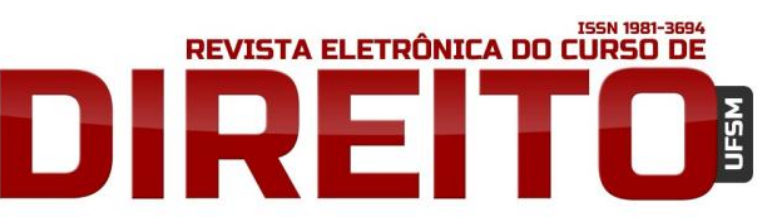

A PROPRIEDADE INTELECTUAL NA ERA DA INFORMAÇÃO: UMA ABORDAGEM HISTÓRICA ACERCA DOS DIREITOS DO AUTOR E A SUA (IN)ADEQUAÇÃO À ATUAL SOCIEDADE EM REDE.

<http://www.publicadireito.com.br/conpedi/manaus/arquivos/Anais/sao_paulo/2535.pdf>. Acesso em: 6 jul. 2013.

CREATIVE COMMONS (CC). Creative Commons website. As licenças. Disponível em: <http://creativecommons.org.br/as-licencas/>. Acesso em: 24 abr. 2013.

CREATIVE COMMONS (CC). Creative Commons website. O que é o CC? Disponível em: <http://creativecommons.org.br/o-que-e-o-cc/>. Acesso em: 21 abr. 2013.

CREATIVE COMMONS (CC). Creative Commons website. Assista apresentação. Disponível em: <http://dl.dropboxusercontent.com/u/102874773/Get-Creative-nova-versao.swf>. Acesso em: 24 abr. 2013.

CONSURMERS INTERNATIONAL. Consumers International's website. Disponível em: <http: / /www.consumersinternational.org/news-and-media/news/2011/04/brazil, -egypt-and-ukamong-worst-copyright-regimes-in-the-world\#.UXA6qKKG021>. Acesso em: 18 abr. 2013.

ESCRITÓRIO CENTRAL DE ARRECADAÇÃO E DISTRIBUIÇÃO. Site Oficial do ECAD. Disponível em: <http: / /www.ecad.org.br/viewcontroller/publico/conteudo.aspx?codigo=138>. Acesso em: 18 abr. 2013.

EVERYTHING is a Remix. Produção de Kirby Ferguson. Disponível em:

<http://www.everythingisaremix.info/watch-the-series/>. Acesso em: 18 abr. 2013.

GIL, Antônio Carlos. Como Elaborar Projetos de Pesquisa. São Paulo: Atlas, 2002.

HAMMES, Bruno Jorge. 0 direito de propriedade intelectual: subsídios para o ensino. São Leopoldo: Editora Unisinos, 1998.

JÚNIOR, Sérgio Vieira Branco. Direitos Autorais na internet e o uso de obras alheias. Rio de Janeiro: Lumen Juris, 2007.

LUHMANN, Niklas. Sociologia do Direito, vol. 1. Rio de Janeiro: Edições Tempo Brasileiro, 1983.

NETTO, José Carlos Costa. Direito Autoral no Brasil. São Paulo: FTD, 1998.

REALE, Miguel apud BASSO, Maristela. O Direito Internacional da Propriedade Intelectual. Porto Alegre: Livraria do Advogado, 2000.

ROHRMANN, Carlos Alberto. O governo da internet: Uma análise sob a ótica do direito das telecomunicações. Disponível em:

<http://www.egov.ufsc.br/portal/sites/default/files/anexos/29538-29554-1-PB.pdf>. Acesso em: 10 jul. 2013.

Recebido em: 30 abr. 2013

Revisões requeridas: 01 jul. 2013

Aprovado em: 11 jul. 2013 